\title{
PREVALENCE OF NEAR MISS AND MATERNAL DEATHS AND ITS MATERNAL AND PERINATAL OUTCOMES: A RETROSPECTIVE STUDY
}

\author{
ANITA MADAN ${ }^{1}$, PALLAVI SHARMA ${ }^{1}$, JAGDEEP KAUR ${ }^{1 *}$, ANISHA PURI ${ }^{2}$ \\ ${ }^{1}$ Department of Obstetrics and Gynecology, Government Medical College, Amritsar, Punjab. ${ }^{2}$ Department of Anaesthesiology and Critical \\ Care, Maharishi Markandeshwar (Deemed to be University), Ambala, Haryana, India. Email: miniy2k4@yahoo.com
}

Received: 25 April 2021, Revised and Accepted: 07 June 2021

\section{ABSTRACT}

Objectives: The objective of the study was to determine maternal mortality ratio (MMR), maternal near miss incidence ratio (MNM IR), MNM to mortality ratio (MNM: MD), and mortality index (MI) and to know the prevalence, demographic distribution, causes and feto-maternal outcome of maternal near miss and maternal deaths.

Methods: A retrospective review of near miss and maternal mortality over a period of 20 months in a tertiary teaching hospital in Punjab.

Results: MMR was 998 MNM IR was 24.20/1000 live births. Maternal near miss mortality ratio was 2.4:1. MI was 29.21\%. The most common cause of maternal mortality was hypertension, which was seen in 14 (53.84\%) women. Among near miss cases, the most common complication noted was hemorrhage, seen in 40 (63.49\%) cases. Among maternal deaths, 7 (26.92\%) women delivered vaginally, $6(23.07 \%)$ women underwent emergency cesarean section. Among near miss cases, 20 (31.74\%) women delivered vaginally, 13 (20.63\%) women underwent cesarean section while $7(11.11 \%)$ had cesarean hysterectomy. Laparotomy for ruptured ectopic pregnancy was done in $6(9.52 \%)$ women, 7 (11.11\%) women had dilatation and evacuation, $3(4.76 \%)$ had exploration of Uterovaginal canal. Preterm birth has seen in $8(12.69 \%)$ in maternal deaths and 23(36.50\%) in maternal near miss. Intrauterine fetal demise occurred in 4 (6.34\%) in maternal deaths and $2(4.87 \%)$ in near miss.

Conclusion: The review of near miss cases is important to identify response of health care system to medical emergencies and provides opportunities to improve the quality of service.

Keywords: Maternal near miss, Maternal mortality, Maternal near miss incidence ratio.

(C) 2021 The Authors. Published by Innovare Academic Sciences Pvt Ltd. This is an open access article under the CC BY license (http://creativecommons.org/ licenses/by/4.0/) DOI: http://dx.doi.org/10.22159/ajpcr.2021v14i8.41893. Journal homepage: https://innovareacademics.in/journals/index.php/ajpcr

\section{INTRODUCTION}

Maternal mortality is a critical indicator to evaluate the quality of maternal healthcare services. Maternal death (as defined by the $9^{\text {th }}$ and $10^{\text {th }}$ revisions of the International Classification of Diseases) is the death of a woman while pregnant or within 42 days of the end of the pregnancy, irrespective of the duration and site of pregnancy, from any cause related to or aggravated by the pregnancy or its management, but not from accidental or incidental causes [1]. Recently maternal near miss is looked on as an additional quality indicator of obstetric care besides maternal mortality. Maternal Near Miss is defined as a woman who survives life threatening conditions during pregnancy, abortion, childbirth or within 42 days of termination of pregnancy irrespective of receiving medical/ surgical interventions [2]. This has gained attention as the major reasons are same for maternal near miss and maternal death but near miss is more prevalent than maternal mortality, and investigating the instances of severe morbidity can identify health system response to maternal emergencies and to identify gaps and conceptualize corrective measures to be taken to improve the services [2]. The Near miss data of regions may be a relevant source of information for policy makers of the region and for selection of maternal health care Priorities and Budget Allocation to Health Systems and Funding of States.

\section{METHODS}

It is a retrospective facility-based review of cases of near miss and maternal mortality that took place over a period of 20 months in a tertiary teaching hospital in Punjab. The observations among Near Miss cases and maternal deaths such as demographic profile of subjects, co-morbidities associated with pregnancy, mode of delivery, causes of maternal morbidity and mortality, neonatal outcome were analyzed.
The data was taken from the maternal deaths record books, admission register and file records of the patients having Near Miss Mortality event during the hospital stay. Near miss events were identified by World Health Organization standard tool relying on clinical, laboratory and management-based criteria.

\section{Inclusion criteria}

The following criteria were included in the study:

Critically ill pregnant, laboring, postpartum, and post-abortal women meeting the following criteria (minimum 3 from each category).

1. Clinical findings (either symptoms or signs)

2. Investigations

3. Interventions.

OR

Any single criteria that signifies cardiorespiratory collapse.

The clinical findings, investigations and interventions were studied under two broad categories

1. Pregnancy specific obstetric and medical disorders - which included hemorrhage, sepsis, hypertension and postpartum collapse

2. Pre-existing disorders aggravated during pregnancy- that included Anemia, respiratory, cardiac, hepatic, neurological dysfunction and endocrine disorders

3. Accidental/Incidental disorders in pregnancy.

Statistical methods

The following indices were calculated:

a. Maternal mortality ratio (MMR) is number of maternal deaths per 1 lac live births (LB). MMR $=$ maternal deaths $/$ LBs $\times 100,000$ 
b. Maternal near miss incidence ratio (MNM IR) refers to the number of maternal near miss cases per $1000 \mathrm{LB}$. MNM IR $=\mathrm{MNM} / \mathrm{LB} \times 1000$

c. Maternal near miss: mortality ratio is the proportion between maternal near miss cases and maternal deaths. Higher ratio indicates better care. MNM: MD

d. Mortality index (MI): Number of maternal deaths divided by the number of women with life threatening conditions expressed as percentage. The higher the index, more women with the life threatening condition dies (low quality of care), while low index suggests better quality of healthcare. [MI = MD/(MNM+MD) $\times 100]$.

\section{RESULTS}

During the review period, there were 2788 deliveries, out of which, there were 2603 LBs. Total number of near miss cases were 63 and there were 26 maternal deaths. MMR is 998 . MNM IR is $24.20 / 1000$ LBs. MNM: MD is 2.4. MI is $29.21 \%$. Demographic profile of maternal near miss and maternal mortality is as below.

Table 1 shows that the most common age group affected in both groups was 25-29 years, $30.7 \%$ in maternal death cases and $41.26 \%$ in near miss cases. There were $4(15.38 \%)$ maternal deaths and $3(4.76 \%)$ near miss cases among women $\leq 20$ years

About 9 (34.61\%) women among maternal deaths were primipara and $17(65.38 \%)$ were multipara. Out of 63 near miss cases, 20 (31.74\%) were primipara and $43(68.25 \%)$ were multipara (Table 2$)$.

About 25 (96.15\%) women among maternal death cases and 60 (95.23\%) among near miss cases were unbooked (Table 3).

Out of 26 maternal deaths, no mortality was seen in the first and second trimester. $23(88.46 \%)$ women presented in the third trimester while $3(11.53 \%)$ presented in the postnatal period. Among near miss cases, $6(9.5 \%)$ presented in first trimester, $4(6.34 \%)$ in the second trimester, $42(66.66 \%)$ in the third trimester while $11(17.46 \%)$ presented in the postnatal period (Table 4).

More than one complication was noted in few patients in both the groups. The most common cause of maternal mortality was hypertension, which was seen in $14(53.84 \%)$ women. Out of 14 deaths due to hypertension, 7 (26.92\%) occurred due to preeclampsia and eclampsia each. The other equally common cause of death was due to pre-existing medical disorder seen in 14 (53.84\%) women, which aggravated the morbidity and resulted in their mortality. Septicemia as the main cause of death was seen in 10 (38.46\%) women. Severe anemia as a cause of death was noted in 5 (19.23\%). Among near miss cases, most common complication noted was hemorrhage, seen in $40(63.49 \%)$ followed by hypertension and pre-existing medical disorders which were seen in 14 (22.22\%) and 12 (19.04\%) women respectively. Out of those who presented with hemorrhage in early pregnancy, 6 (9.52\%) had ruptured ectopic pregnancy. In patients with hemorrhage in late pregnancy, $15(23.80 \%)$ had major degree placenta previa with or without morbidly adherent placenta and $8(12.69 \%)$ had postpartum hemorrhage (Table 5).

Among maternal deaths, maximum women 10 (38.46\%) expired undelivered. 7 (26.92\%) women delivered vaginally, 6 (23.07\%) women underwent emergency cesarean section. Out of 3 maternal mortality patients who reported in the postpartum period, 1 (3.84\%) underwent dilatation and evacuation and $2(7.69 \%)$ were managed conservatively.

Table 1: Distribution according to age

\begin{tabular}{lll}
\hline Age group (in years) & MDR $(\mathbf{n = 2 6 )}(\%)$ & Near miss $(\mathbf{n = 6 3 )}(\%)$ \\
\hline$\leq 20$ & $4(15.38)$ & $3(4.76)$ \\
$21-24$ & $5(19.23)$ & $16(25.39)$ \\
$25-29$ & $8(30.7)$ & $26(41.26)$ \\
$30-34$ & $4(15.38)$ & $13(20.63)$ \\
$\geq 35$ & $5(19.29)$ & $5(7.9)$ \\
\hline
\end{tabular}

Among near miss cases, 20 (31.74\%) women delivered vaginally, $13(20.63 \%)$ underwent cesarean section, 7 (11.11\%) had cesarean hysterectomy and 1 (1.58\%) underwent laparotomy for rupture uterus. Laparotomy for ruptured ectopic pregnancy was done in 6 (9.52\%) women, 7 (11.11\%) had dilatation and evacuation. Among near miss women presenting in postpartum period, $3(4.76 \%)$ had exploration of Uterovaginal canal (UV Canal), 1 (1.58\%) each had laparotomy for uterine perforation and laparotomy for traumatic PPH and 4 (6.34\%) postpartum patients were managed conservatively (Table 6).

Among maternal mortality patients, 13 women delivered, out of which, $8(12.69 \%)$ had preterm babies, $4(6.34 \%)$ had intrauterine fetal demise and only 1 (7.69\%) full term baby. Among near miss cases, 41 women delivered, out of which, $23(36.50 \%)$ had preterm babies, $16(39.02 \%)$ had full term babies and 2 (4.87\%) had intrauterine fetal demise (Table 7).

\section{DISCUSSION}

In this study, MMR is 998 that is comparable to study by Sarma et al. [3] who reported MMR of 1085.

MNM IR in the present study is $24.20 / 1000$ LBs which is comparable MNM IR of 31.4/1000 study by Sultana et al. [4].

MNM: MD is 2.4, which is comparable to 2.6:1 as reported by Parmar et al. [5].

MI is 29.21\%, which is comparable to MI of $32.7 \%$ Bansal et al. [6].

The most common age group affected in both groups in present study was 25-29 years, $30.7 \%$ in maternal death cases and $41.26 \%$ in near miss cases, which is comparable to study by Oladapo et al. [7], which reported $29.5 \%$ and $26.5 \%$ patients in maternal death and near miss cases belonging to $26-29$ years age group.

About 17 (65.38\%) women among maternal death cases while $43(68.25 \%)$ near miss cases were multipara which is comparable to study by Oladapo et al. [7] in which $56.8 \%$ and $53.6 \%$ maternal mortality and near miss cases were multipara.

About 25 (96.15\%) women among maternal death cases and 60 (95.23\%) among near miss cases were unbooked which is comparable to that reported by Oladapo et al. [7]

Table 2: Distribution according to parity

\begin{tabular}{lll}
\hline Parity & MDR $(\mathbf{n}=\mathbf{2 6})(\%)$ & Near miss $(\mathbf{n}=63)(\%)$ \\
\hline Primipara & $9(34.61)$ & $20(31.74)$ \\
Multipara & $17(65.38)$ & $43(68.25)$ \\
\hline
\end{tabular}

Table 3: Distribution according to previous antenatal checkups

\begin{tabular}{lll}
\hline $\begin{array}{l}\text { Previous antenatal } \\
\text { checkups }\end{array}$ & $\begin{array}{l}\text { MDR } \\
(\mathbf{n = 2 6 )}(\%)\end{array}$ & $\begin{array}{l}\text { Near miss } \\
(\mathbf{n = 6 3 )}(\%)\end{array}$ \\
\hline Booked & $1(3.84)$ & $13(20.63)$ \\
Unbooked & $25(96.15)$ & $60(95.23)$ \\
\hline
\end{tabular}

Table 4: Distribution according to antenatal or postnatal presentation at the time of admission

\begin{tabular}{lll}
\hline $\begin{array}{l}\text { Presentation } \\
\text { at admission }\end{array}$ & $\begin{array}{l}\text { MDR } \\
(\mathbf{n = 2 6 )}(\mathbf{\%})\end{array}$ & $\begin{array}{l}\text { Near miss } \\
(\mathbf{n = 6 3 )} \mathbf{( \% )}\end{array}$ \\
\hline $\begin{array}{l}\text { Antenatal } \\
1^{\text {st }} \text { trimester }\end{array}$ & $0(0)$ & $6(9.5)$ \\
$2^{\text {nd }}$ trimester & $0(0)$ & $4(6.34)$ \\
$3^{\text {rd }}$ trimester & $23(88.46)$ & $42(66.66)$ \\
Postnatal & $3(11.53)$ & $11(17.46)$ \\
\hline
\end{tabular}


Table 5: Distribution of various complications in both groups

\begin{tabular}{lll}
\hline Cause & $\begin{array}{l}\text { MDR } \\
(\mathbf{n = 2 6 )} \mathbf{( \% )}\end{array}$ & $\begin{array}{l}\text { Near Miss } \\
(\mathbf{n = 6 3 )}\end{array}$ \\
\hline $\begin{array}{l}\text { Hemorrhage } \\
\text { Early pregnancy }\end{array}$ & $1(3.84)$ & $40(63.49)$ \\
$\quad$ Ectopic pregnancy & $0(0)$ & $6(9.52)$ \\
Abortion & $0(0)$ & $7(11.11)$ \\
Late pregnancy & & \\
$\quad$ Placenta previa & $1(3.84)$ & $15(23.80)$ \\
Abruptio placentae & 0 & $4(6.34)$ \\
Postpartum hemorrhage & 0 & $8(12.69)$ \\
Hypertension & $14(53.84)$ & $14(22.22)$ \\
Pre-eclampsia & $7(26.92)$ & $8(12.69)$ \\
Eclampsia & $7(26.92)$ & $6(9.52)$ \\
Sepsis & $10(38.46)$ & $3(4.76)$ \\
Rupture uterus & $0(0)$ & $2(3.17)$ \\
Severe anemia & $5(19.23)$ & $9(14.28)$ \\
Medical disorder & $14(53.84)$ & $12(19.04)$ \\
Other & $4(17.39)$ & $0(0)$ \\
\hline
\end{tabular}

Table 6: Distribution of mode of delivery/termination of pregnancy

\begin{tabular}{lll}
\hline Interventions & $\begin{array}{l}\text { MDR } \\
(\mathbf{n = 2 6 )}(\%)\end{array}$ & $\begin{array}{l}\text { Near miss } \\
(\mathbf{n = 6 3 )} \mathbf{( \% )}\end{array}$ \\
\hline Undelivered & $10(38.46)$ & $0(0)$ \\
Vaginal delivery & $7(26.92)$ & $20(31.74)$ \\
LSCS & $6(23.07)$ & $13(20.63)$ \\
Laparotomy for rupture uterus & $0(0)$ & $1(1.58)$ \\
Laparotomy for ruptured ectopic & $0(0)$ & $6(9.52)$ \\
Dilatation and evacuation & $1(3.84)$ & $7(11.11)$ \\
Conservative management in & $2(7.69)$ & $4(6.34)$ \\
postpartum patients & & $7(11.11)$ \\
Cesarean hysterectomy & 0 & $3(4.76)$ \\
Exploration of UV canal & 0 & $1(1.58)$ \\
Laparotomy for uterine perforation & 0 & $1(1.58)$ \\
Laparotomy for traumatic PPH & 0 &
\end{tabular}

UV: Uterovaginal

Table7: Neonatal outcome in maternal mortality and near miss groups

\begin{tabular}{lll}
\hline Outcome & MDR (n=13) (\%) & $\begin{array}{l}\text { Near miss } \\
(\mathbf{n = 4 1 )}(\%)\end{array}$ \\
\hline Alive term babies & $1(7.69)$ & $16(39.02)$ \\
Alive preterm babies & $8(12.69)$ & $23(36.50)$ \\
IUFD & $4(6.34)$ & $2(4.87)$ \\
\hline
\end{tabular}

Sarma et al. [3] in which 72.7\% near miss cases saw 23 (88.46\%) maternal mortality and $42(66.66 \%)$ near miss cases in women presenting in the third trimester, which is comparable to study, and $41.2 \%$ maternal mortality was observed in third trimester. In our study, 3 (11.53\%) maternal mortality and 11 (17.46\%) near miss cases presented in the postnatal period comparable to $12.1 \%$ and $41.2 \%$ maternal mortality in near miss and maternal deaths respectively by Sarma et al. [3]. As our center is a tertiary care center where patients are referred from various Primary Health Centers (PHCs) and Community Health Centers (CHCs) of adjoining districts of Punjab, most women with complications presented late due to the late diagnosis, delayed referral and distance related problems.

The most common cause of maternal mortality was hypertension, which was seen in 14 (53.84\%) women. The other equally common cause of death was due to pre-existing medical disorder seen in $14(53.84 \%)$ women which is comparable to causes reported by Doreswamy [8] 22.22\% each. Septicemia as the main cause of death was seen in 10 (38.46\%) women. Among near miss cases, most common complication noted was hemorrhage, seen in 40 (63.49\%) cases followed by hypertension and pre-existing medical disorders which were seen in 14 (22.22\%) and 12 (19.04\%) women respectively which is comparable to causes reported by Doreswamy [8] in which hemorrhage was the main cause $-85.2 \%$, followed by hypertension in pregnancy $-11.7 \%$.

Among maternal deaths, 10 (38.46\%) women expired undelivered. 7 (26.92\%) women delivered vaginally, 6 (23.07\%) women underwent emergency cesarean section. Among near miss cases, 20 (31.74\%) women had vaginal delivery, 13 (20.63\%) underwent cesarean section and 7 (11.11\%) had cesarean hysterectomy. Laparotomy for ruptured ectopic pregnancy was done in $6(9.52 \%)$ women while $7(11.11 \%)$ had dilatation and evacuation. Among near miss cases presenting in postpartum period, $3(4.76 \%)$ had exploration of UV canal. These outcomes are comparable to outcomes reported by Sarma et al. [3].

Among maternal mortality patients, 8 (12.69\%) had preterm babies $4(6.34 \%)$ had intrauterine fetal demise. Among near miss cases, $23(36.50 \%)$ had preterm babies, $16(39.02 \%)$ had full term babies and $2(4.87 \%)$ had intrauterine fetal demise. This differs slightly from perinatal outcomes in study by Doreswamy [8] 5.8\% preterm babies, $64.7 \%$ term babies and $17.6 \%$ intrauterine fetal demise. The variation is due to difference in gestational age at presentation in their study.

\section{CONCLUSION}

Early detection of high-risk pregnancies and their timely referral to tertiary care center is very important. Promoting institutional deliveries and positioning of skilled work force at first contact center can play crucial role in reducing maternal mortality and near miss maternal events. Evaluating near miss events can help in creating safer and more approachable obstetric healthcare for future patients. Maternal mortality rate in our center is higher due to poor antenatal care at place of registration in peripheral Health care centers, and lack of skilled personnel, resources and preparedness for emergencies at subcenter, PHC and CHC levels and delayed referrals to tertiary care center. A regular audit of near miss would facilitate collection of information regarding these delays. Knowledge about the circumstances that improved survival and recovery may lead to corrective steps in future for reducing deaths due to near miss scenario.

\section{AUTHORS CONTRIBUTION}

Dr. Anita Madan and Dr. Pallavi Sharma conceived the idea of this study "Prevalence of Near miss and Maternal deaths and its Maternal and perinatal outcomes: A Retrospective study.” Dr. Jagdeep Kaur developed the theory and computations. Dr. Anita Madan, Dr. Pallavi Sharma and Dr. Jagdeep kaur verified the analytical methods. Dr. Anisha Puri encouraged Dr. Jagdeep kaur to investigate. All authors discussed the results and contributed to final manuscript.

\section{CONFLICTS OF INTEREST}

The authors declare that there are no conflicts of interest.

\section{AUTHOR'S FUNDING}

The authors received no financial support for the research and/or publication of this article.

\section{REFRENCES}

1. Say L, Souza JP, Pattinson RC; WHO Working Group on Maternal Mortality and Morbidity Classifications. WHO working group on Maternal Mortality and Morbidity Classifications. Maternal near misstowards a standard tool for monitoring quality of maternal health care. Best Pract Res Clin Obstet Gynaecol 2009;23:287-96.

2. Ministry of Health and Family Welfare. Matenal Near Miss Review Operational Guidelines. New Delhi: Ministry of Health and Family Welfare Government of India; 2014.

3. Sarma HK, Sarma HK, Kalita AK. A prospective study of maternal near 
miss and maternal mortality cases in FAAMCH, Barpeta; with special reference to its aetiology and management: First 4 months report. J Obstet Gynaecol Barpeta 2015;1:100-6.

4. Sultana S, Ishtiaque S, Fareed S, Kamal S, Aslam Z, Hussain R, et al. Clinical spectrum of near-miss cases in obstetrics. Cureus 2019;11:e4641.

5. Parmar NT, Parmar AG, Mazumdar VS. Incidence of maternal "nearmiss" events in a tertiary care hospital of central Gujarat, India. J Obstet Gynecol India 2016;66:315-20.
6. Bansal M, Lagoo J, Pujari K. Study of near miss cases in obstetrics and maternal mortality in Bastar, Chattisgarh, India. Int J Reprod Contracept Obstet Gynecaal 2016;5:620-3

7. Oladapo OT, Sule-Odu AO, Olatunji AO, Daniel OJ. "Near-Miss" obstetric events and maternal deaths in Sagamu, Nigeria: A retrospective study. Reprod Health 2005;2:9.

8. Doreswamy N. Prevalance and outcome of maternal near miss in a tertiary care centre a cross sectional study at Hassan, Karnataka, India. Int J Clin Obestet Gynaecol 2020;4:209-12. 